\title{
INTERPRETACIÓN DE NOMBRES TOPÓNIMOS DE TACNA
}

\author{
Oscar Mamani Aguilar \\ Francisca Elena Yucra Yucra²
}

\section{RESUMEN}

El presente trabajo interpreta algunos nombres toponímicos de la ciudad de Tacna, identificando como problema la carencia de estudios científicos que causa el deterioro de la identidad cultural, confusiones o problemas de aculturación en los pobladores.

Se ha tomado como referencia a renombrados estudiosos como los doctores Rodolfo Cerrón - Palomino, Juan Carlos Godenzzi, Rodolfo Sánchez, quienes dan un soporte teórico argumentando que los nombres de los lugares tienen una justificación histórica. El testimonio de los propios pobladores de edad avanzada dan pistas para una adecuada interpretación lingüístico, apoyado con algunos elementos de prueba. Siendo la metodología de trabajo el análisis crítico reflexivo, tomando en cuenta los diversos aspectos culturales, políticos, lingüísticos que fortalecen al desarrollo de la lengua aimara.

Aquí pretendemos demostrar científicamente dos nombres de lugares de la ciudad de Tacna, que actualmente se denomina "Calana y Camilaca". Dichos nombres aún no están explicados científicamente. Para tener una identidad cultural genuino, es posible desarrollar el análisis linguístico - morfológico. Sin lugar a dudas corresponden al léxico aimara, "Qala:na" y "Qamiri Laq'a", que tienen suficiente justificación para su validez.

Con el análisis lingüístico - morfológico de las palabras "Calana" y "Camilaca" es posible reconstruir el origen aimara de los lugares. Qala:na" y "Qamiri Laq'a" son los primeros hitos que permitirán replantear el significado del nombre de cada lugar, con la finalidad de fortalecer la identidad cultural de los pobladores. El topónimo "Tacna", proviene de la voz aimara "T'aqaña" que significa división o repartición de tierras, que posteriormente demostraremos los hechos evidentes a esta afirmación.

\footnotetext{
'Doctor en Educación, Magíster en Lingüística Andina en Educación, Licenciado en Educación en Lengua, Literatura, Psicología y Filosofía, especialización en Educación Intercultural Bilingüe.

${ }^{2}$ Licenciada en Educación en Lengua, Literatura, Psicología y Filosofía, especialización en Educación Intercultural Bilingüe
} 


\section{INTRODUCcIóN}

El presente artículo engloba la iniciación del trabajo de análisis morfológico lingüístico de dos nombres de lugares de la ciudad de Tacna, denominados "Calana" y "Camilaca". El primero de los nombres proviene del término genuino aimara [Qala:na], que significa "lugar pedregoso" o "amontonamiento de piedras cerca del riachuelo" y el segundo nombre "Qamiri Laq'a" es una palabra compuesta que proviene de la voz aimara "Qamiri", que significa persona poderosa, rico o persona que posee abundancia de bienes, luego el término aimara "Laq'a", significa "tierra" y las dos palabras juntas "Qamiri Laq'a" científicamente significa "rica tierra que da buenos frutos". Antiguamente fue habitado por los hacendados o terratenientes. Además, el origen del nombre de "Tacna", muy probablemente tenga el origen aimara, porque Manuel Quiroga, estudioso de la raiciología, afirma: "Tacna proviene de voces aymaras "Ta (arranque), $\mathrm{Ka}$ (divide) y $\mathrm{Na}$ (asiento]. Osea, asiento o lugar de división o partición. Además, fundamenta dicha interpretación en el sentido de que las tribus primitivas al llegar al valle se repartieron las tierras para el cultivo y levantamiento de sus viviendas".

El análisis de los nombres "Qala:na" y "Qamiri Laq'a" está demostrado lingüísticamente que son léxicos aimaras. además, hay suficientes evidencias históricos, culturales y testimonios de los pobladores que respaldan su autenticidad. Este estudio de análisis crítico reflexivo es la iniciación para interpretar nombres de lugares con el fin de buscar mejor identidad cultural de los pobladores de Tacna.

\section{Planteamiento del problema}

En la ciudad de Tacna, no hay estudios toponímicos que expliquen e interpreten científicamente los nombres de lugares con su verdadero significado, de parte de los profesionales de diferentes ramas como antropólogos, lingüistas, agrónomos, sociólogos, educadores y otros; sin embargo, desde el análisis lingüístico morfológico es posible demostrar la autenticidad de los nombres de lugares, con la finalidad de contribuir con los pobladores de diferentes edades, quienes se sienten confundidos o avergonzados con su lugar de origen por desconocimiento del verdadero nombre del lugar, lo cual ha causado a los pobladores el deterioro de la identidad cultural con su comunidad, barrio, sector entre otros.

No obstante que, los nombres de lugares están registrados desde la antigüedad con razones debidamente justificadas, la invasión española al territorio peruano, cuya forma de vida de la población extranjera ha transgredido el nombre genuino de lugares con la castellanización del monolingüe hispano, en consecuencia, la asignación de nombres aimara o quechua fueron castellanizadas, y la castellanización no tiene ningún sentido o significado para la correcta interpretación y explicación de topónimos. Para dar su real dimensión a los nombres de lugares y para explicar este fenómeno que causa confusiones, se requiere del dominio de la la lengua quechua y/o aimara, conocimiento teórico que permita deslindar la interpretación, ya que encontramos muchos nombres de lugares registrados en diversos documentos, que no están adecuadamente expresados en un contexto multilingüe y pluricultural como es la región de Tacna.

\section{Marco teórico}

Tenemos algunos estudiosos que ha tratado sobre el estudio de topónimos, 
así, el Dr. Cerrón Palomino (1990), en relación a nombres topónimos manifiesta que los: "... nombres de lugares de la sociedad peruana se debe a algún acontecimiento histórico o por su geografía física, que en el Perú en su mayoría están expresadas en el idioma quechua, aimara o puquina ... sin embargo, con la castellanización ha sufrido muchas variaciones..."

Rodolfo Sánchez (2008), en la Revista Intercultural Quechua Aimara, en una entrevista relacionada con nombres de lugares del Perú, afirma: "Definitivamente, algunos estudiosos han demostrado, principalmente lingüistas y antropólogos, entre otros, que los nombres de lugares que actualmente observamos están cambiados en su escritura, pero en su forma de pronunciación se mantiene, lo que falta es una interpretación minuciosa que justifique su verdadero nombre originario..." (CEPCLA, 2008).

El Dr. Juan Carlos Gedenzzi, manifiesta: "para expresar el verdadero sentido de la palabra quechua se debe analizar la estructura de la palabra raíz y la constitución de sufijos ..." (Revista Allpanchis, 2007: 138)

Oscar Mamani y F, Elena Yucra, en su libro fonética y fonología quechua y aimara, afirman: "... para interpretar el verdadero nombre de los lugares de Puno, es indispensable conocer y manejar la estructura interna de la lengua aimara en su aspecto fonético, fonológico, morfológico, sintáctico y semántico", y como ejemplo se interpreta el nombre topónimo de: "Huacani".

1. "Huacani", nombre de un Centro Poblado del distrito de Pomata, provincia de Chucuito, departamento de Puno.
2.El término "Huacani", sin la debida interpretación sociolingüística histórica no tiene significado en el idioma castellano.

3. El análisis morfológico del término "Huacani". La estructura interna de la palabra "Huacani" proviene del morfema inicial aimara, "wak'a-" y el sufijo "-ni". Esta palabra en castellano significa "prenda de vestir que sirve para ponerse en la cintura del hombre con fines de asegurar el pantalón o para realizar trabajos que requiere mayor esfuerzo y para las mujeres sirve para sujetarse las polleras, sujetarse la cintura para llevar cargas pesadas. Se trata entonces de una faja tejida de lana que sirve para colocarse en la cintura para múltiples usos. El sufijo "-ni" es un sufijo posesivo y que significa "que tiene algo".

Históricamente, los antiguos pobladores del Centro Poblado de Huacani, fueron eminentemente agricultores por su especial microclima de la zona y utilizaban esta vestimenta llamado "wak'a" para sujetarse la cintura y realizar trabajos que requieren mayor esfuerzo durante varias jornadas de trabajo, sin sentir el menor cansancio.

Lingüísticamente, la palabra "Huacani" es un término aimara que correctamente debe escribirse [Wak' ani]. Significa prenda de vestir que sirve para sujetarse la cintura con fines de realizar trabajos forzados ...". (Mamani A. Oscar y F. Elena Yucra Yucra, 2010: 28)

Los historiadores Carlos Auza y Cuneo Vidal, refiriéndose a nombre de lugares, afirman: "Calana, el que se deriva de las voces aymaras "Kaala hana", lugar con abrigo de piedras, amontonamiento de piedras o lugar pedregoso". Luego, en 
relación al nombre "Camilaca", manifiestan: "Camilaca es una palabra de origen aymara que significa "tierra rica", ya que "Cami", significa "rica" y "Laca" es "tierra" ...o tierra de los camires o hacendados, tierra buena, "tierra asendosa fértil y de mucho fruto". Además, existen otras versiones, pero sin mayor sustento teórico.

Teniendo en cuenta las bases teóricas de destacados estudiosos, los nombres topónimos "Calana y Camilaca" de la región de Tacna, se pueden interpretar y explicar desde diferentes puntos de vista. Así la doctora Teresa Valiente (2008) dice: "los topónimos de cualquier lugar corresponden a una historicidad, describen aspectos geográficos, desarrollan acontecimientos históricos entre otros aspectos...".

Sin embargo, los nombres topónimos de la región de Tacna, no están suficientemente investigados $\mathrm{ni}$ explicados con su verdadero nombre genuino de cada lugar; este hecho implica que los pobladores de la región, desconocer el verdadero significado de los topónimos, por ende, los pobladores no se sienten plenamente identificados con su valor cultura, pues que guarda un tesoro de mucha importancia para su interpretación y explicación. A continuación mostramos algunos nombres de la región: Tacna, Arunta, El Cerro Inti Orco, Pocollay, Pachia, Calana, Ilabaya, Tarata, Ticaco, Candarave, Tutupaka, Cairani, Curibaya, Sama, etc.

Para interpretar y explicar el correcto significado de los topónimos de la región de Tacna es indispensable el dominio de la lengua quechua y/o aimara. Incluso para poder explicar desde los diferentes enfoques filosóficos, culturales, lingüístico, sociológicos, económicos, políticos entre otros.

La metodología de trabajo que se aplicó en el presente estudio fue el análisis crítico reflexivo, que consistió en buscar evidencias e informaciones que permita validar el significado de nombres toponímicos.

\section{Análisis de topónimos de Tacna}

Aquí, presentamos una breve explicación e interpretación del topónimo de la palabra aimara "Calana", "Camilaca" y "Tacna", que tienen un significado que repercute positivamente en el desarrollo de la sociedad tacneña.

\section{A) Calana}

El nombre "Calana" está asignado a un determinado lugar que se encuentra en la parte norte de la ciudad de Tacna, cuya significancia es:

\section{a) Geográficamente}

Para los pobladores de la región de Tacna, el nombre denominado "Qala:na" presenta un lugar con abundancia piedra del río o lugar de tierra pedregosa"que definitivamente respalda el nombre genuino para su correcta interpretación.

\section{b) Lingüísticamente}

El término "Calana" proviene de la voz aimara, "Qala" que significa "piedra" y el sufijo "- na" ["en"] ubicación, lugar, por tanto, la palabra "Calana" , lingüísticamente escrita en el idioma aimara es "Qala:na". Expresa que en el tiempo pasado, en el lugar existía abundancias piedras del río o se apreciaba pedregoso,lo cual es posible verificar 
hasta la fecha.

El análisis del término "Qala:na", con el testimonio del señor Andrés Mamani de 83 años, natural de Tarata, quien manifiesta: "Antiguamente, cuando llegaron las personas del altiplano en busca de tierras, por sector, dicen que limpiaban las piedras y piedrecillas para convertirlo en tierra de cultivo, y plantar árboles frutales o hacer chacra ... porque antes, había cantidad de terrenos sin cultivar por falta de agua, así actualmente existe inmensos terrenos en Majes sin cultivar por la falta de agua " (Entrevista 12-10-2013).

Otra entrevista se realizó al abuelo Marcelino Quille de 92 años, quien hizo la migración de Puno desde niño, y actualmente vive en la asociación El Morro de la ciudad de Tacna, quien nos hace saber lo siguiente:

"Yo, cuando era niño más o menos 06 años llegué a Tacna, mis tíos me han traído y buscábamos trabajo, solamente había chacras por la zona de "Pueblo Joven La Natividad", por Yarara, Locumba, y por el sectorde Calana, todo era una pampa arenal pedregosa, no había casas ni chacras, hasta daba miedo para caminar, porque era todo vacío, nadie quería esas tierras pedregosas y recién últimos 40 años más o menos, con la invasión de terrenos se han poblado, tampoco nadie se atajaba de los terrenos porque no había agua para hacer chacras, ..." (Entrevista 18-10-2013).

\section{c) Filosóficamente}

Los pobladores del distrito de Calana, en su mayoría son aimaras. Radican muchos años en la ciudad de Tacna a lo que consideran como ciudad de oportunidades.
Existe una relación directa entre el hombre y la naturaleza, llamada "Pacha Mama". Es permanente el diálogo para la vida. Se pide y se le agradece Las diversas peticiones son para tener una buena salud, estudio, trabajo, etc. Los ritos ceremoniales se celebra en el mes de agosto de cada año.

\section{d) Económicamente}

"Calana" se caracteriza por ser una zona agrícola de gran potencial turístico, existen Restaurantes que expenden variedad de potajes, altamente apreciado por los visitantes.

Por lo tanto, a través del estudio lingüístico - morfológico, antropológico y la historicidad es posible demostrar el verdadero nombre del lugar que "Calana" proviene de la voz aimara "Qala:na" , lugar que antiguamente fue pedregoso. En la actualidad por los airededores existen montones de arena con piedrecillas del río, inclusive algunos pequeños canchones están construidas con esas piedrecillas.

\section{B) El topónimo Camilaca}

1. El nombre "Camilaca", se debe a la existencia de tierras arenosas y microclima templaba, adecuado para la producción agrícola, y ganadera.

2. El término "Camilaca", proviene de la voz aimara "Qamiri Laq'a", tierra de abundancia de bienes.

3. El término "Camilaca" lingüísticamente pertenece al idioma aimara. La palabra "Camilaca" está compuesta por dos voces, la raíz "Qamiri-", persona que posee muchos bienes y el topónimo "laq'a", que siginfica "tierra". Significa "tierra arenosa, fértil y de mucha abundancia de 
productos, que hace convertir a la persona en rica y poderosa.

4. Históricamente, Francisco Pariguana de 96 años de edad, poblador de la Asociación Santa Teresita del distrito de Gregorio Albarracin Lanchipa de la ciudad de Tacna, afirma: "En aquel tiempo, las tierras no tenían dueño, todo era común, pero había gente aliado con los curas, quienes se apropiaban de las tierras arenosas que tenían agua y pastizales para enriquecerse poderosamente de chacra y animales, así fue Camilaca".

Podemos afirmar que, el topónimo "Camilaca" es un término aimara y consecuentemente debe escribirse, para todos los casos en la lengua aimara como "Qamiri Laq'a", que significa lugar de existencia de la tierra rica y arenosa que da buenos frutos.

Por otra parte intentamos interpretar el topónimo "Tacna", según algunas referencias bibliográficas y manifestaciones de los antiguos pobladores, se precisa que, en la época antigua, todas las tierras eran libres, nadie era dueño y con el crecimiento de la población y por el intercambio de productos de un lugar a otro, los pobladores del altiplano habrían venido a posesionarse de ellas y repartirse para el cultivo y levantar su vivienda. "Tacna" o "T'aqaña" es léxico aimara, que significa división o repartición de tierras para el cultivo.

\section{Conclusión}

En conclusión, los topónimos "Qala:na", "Qamiri Laq'a" han sufrido cambios en la escritura con la educación hispana, pero a nivel fonético y fonológico mantiene su nombre genuino. Con el tiempo y con la castellanización quedó fijada como "Calana", "Camilaca", cuyo efecto dio la pérdida del valor histórico y cultural. Sin embargo, con el análisis lingüístico morfológico de la lengua aimara, es posible reconstruir su nombre originario que provienen del término "Qala:na", "Qamiri Laq'a", y que ambos términos con el significado descrito anteriormente.

También damos el inicio para establecer el significado verdadero de "Tacna" que muy probablemente proviene de la voz aimara "T'aqaña", que significa división de tierras sin dueño para la agricultura. Contamos con suficientes evidencias para rectificar las afirmaciones de muchos estudiosos, profesionales de otras ramas que han causado ciertas confusiones que repercute negativamente para el desarrollo de la identidad cultural y lingüístico de la sociedad tacneña.

\section{Aporte para la ciencia}

Para hacer un análisis lingüístico morfológico de los topónimos es indispensable que se conozca y maneje el aspecto fonético, fonológico, morfológico, sintáctico, semántico de la lengua quechua y aimara y así realizar una adecuada explicación científica de los topónimos que en el Perú, están en el idioma quechua o aimara. Los topónimos "Calana, Camilaca y Tacna" son expresados en la lengua aimara como

"Qala:na",

\section{"Oamiri Laq'a" y "T'aqaña".}

Este resultado de la investigación lingüística es el inicio para interpretar otros y diversos nombres toponímicos, a fin de aclarar las confusiones que ha causado a los pobladores, lo cual repercute negativamente y contribuye en el deterioro de la identidad cultural y lingüístico de la región sur del Perú. 


\section{REFERENCIAS BIBLIOGRÁFICAS}

BALLON AGUIRRE, Enrique 1989 DIGLOSIA LINGUO-LITERATURA $Y$ EDUCACIÓN EN EL PERÚ. Impreso en el Perú.

CERRÓN PALOMINO, Rodolfo1996 LINGÜÍSTICA AIMARA. Editorial Centro de Estudio Rurales Andinos Bartolomé de las Casas" Cusco-Perú.

CERRÓN PALOMINO, Rodolfo 1996 LINGÜÍSTICA QUECHUA. Editorial Centro de Estudio Rurales Andinos Bartolomé de las Casas" Cusco-Perú.

GODENZZI ALEGRE, Juan C. 1999 TRADICIÓN ORAL ANDINA Y AMAZONIA.. PROEIB-Andes, Cochabamba-Bolivia.
HUAYHUA PARI, Felipe 2000 GRAMÁTICA DESCRIPTIVA DE LA LENGUA AIMARA. Edición: Negocios Arco Iris S. R.L.

HURTADO DE MENDOZA, William 2001 PRAGMÁTICA DE LA CULTURA Y LALENGUA QUECHUA. Ediciones Universidad Nacional Agraria La Molina.

MAMANI A., O. Y F.ELENA YUCRA 2010 FONÉTICA Y FONOLOGIA DE LA QUECHUA Y AIMARA. Ediciones UNA. Puno.

\section{Correspondencia}

Oscar Mamani Aguilar Jilataoscar123@yahoo.es 